\title{
Preparation of Cementitious Material Using Smelting Slag and Tailings and the Solidification and Leaching of $\mathbf{P b}^{2+}$
}

\author{
Dan Zhang, ${ }^{1,2}$ Shiliu Shi, ${ }^{3}$ Chengbiao Wang, ${ }^{1}$ Xiaocong Yang, \\ Lijie Guo, ${ }^{2}$ and Shanshan Xue ${ }^{2}$ \\ ${ }^{1}$ School of Engineering Technology, China University of Geosciences, Beijing 100083, China \\ ${ }^{2}$ Beijing General Research Institute of Mining \& Metallurgy, Beijing 110160, China \\ ${ }^{3}$ School of Materials Sciences and Technology, China University of Geosciences, Beijing 100083, China \\ Correspondence should be addressed to Dan Zhang; dzdxzd@163.com
}

Received 11 July 2014; Accepted 16 September 2014

Academic Editor: Zhaohui Li

Copyright (C) 2015 Dan Zhang et al. This is an open access article distributed under the Creative Commons Attribution License, which permits unrestricted use, distribution, and reproduction in any medium, provided the original work is properly cited.

\begin{abstract}
The composite cementitious materials were prepared with lead-zinc tailings, lead-zinc smelting slag, and cement clinker. The effect of material ratio on the mechanical properties, the phase analysis, and microstructures were investigated. The effect of the $\mathrm{pH}$ and stripping time on the leaching amount of lead ion was discussed. The results show that the additive amount of the tailings should be minimized for the cementitious materials meeting the strength requirements, controlled within 10\%. The leaching amount of cementitious materials remains low in a larger range of $\mathrm{pH}$, which can effectively reduce the leaching of heavy metal lead. The leaching kinetics of lead ions in the three kinds of samples could be better described by the pseudo-second-model.
\end{abstract}

\section{Introduction}

In the process of exploiting and utilizing of mineral resource, a series of environmental problems have been arisen. The exploitation of the mine will produce a lot of waste rock and gob, resulting in waste of resources and security risks. The stacking of tailings from concentration and smelting slag, sludge, and dust from metallurgical process have stolen the land resources which produce a serious pollution to the environment. Filling the gobs with tailings and other solid waste can not only realize the control of solid waste pollution and improve the utilization of the land but also prevent the surface subsidence and improve the mining index. However, if tailings and other solid waste are directly used to fill the gobs, it will be prone to oxidation and ion release in the rain, the sun, and other natural stress; toxic substances and heavy metal ions can be released to the environment as well. A tailings dam leakage occurred in Spanish Aznalcollar sulfur iron mine in April 1998, resulting in the decline of the $\mathrm{pH}$ values in the vicinity of the local underground water and the concentration of heavy metal ions $\mathrm{Zn}, \mathrm{Mn}, \mathrm{Co}, \mathrm{Pb}, \mathrm{Cd}$, and $\mathrm{Tl}$ in underground water and soil was significantly increased
[1]. Sharma and Al-Busaidi investigated the changes of underground water metal ion concentration and $\mathrm{pH}$ value through the analysis of 12 years monitoring data of soil and water around the copper mine tailings of Oman Mine Company $[2,3]$ and confirmed the pollution of groundwater tailings. Shaw monitored that the $\mathrm{Hg}$ concentrations in surface water and groundwater continued to rise although the Murray Brook gold mine in Canada had been closed for 10 years [4]. Therefore, the tailing cannot be used to fill the gobs directly. It had been confirmed that heavy metals could be solidified in cement clinker crystalline lattice in the process of cement kiln incinerating solid waste. These elements would be compacted in the C-S-H consolidation gel or exist in small pores after cement hydration and were not willing to release under natural conditions. Via the use of the cement, heavy metals and other harmful substances are not released into the environment which can eliminate the hidden dangers of pollution. The preparation of cementitious material with tailings to replace a part of cement can not only meet the requirement of structure and high strength but also reduce the cost. The purpose of effectively recycling tailings and other waste was achieved [5]. 
TABLE 1: Chemical composition of raw materials/\%.

\begin{tabular}{lcccccccccccccc}
\hline Composition & $\mathrm{CaO}$ & $\mathrm{SiO}_{2}$ & $\mathrm{Al}_{2} \mathrm{O}_{3}$ & $\mathrm{MgO}$ & $\mathrm{Fe}_{2} \mathrm{O}_{3}$ & $\mathrm{MnO}$ & $\mathrm{K}_{2} \mathrm{O}$ & $\mathrm{TiO}_{2}$ & $\mathrm{FeO}$ & $\mathrm{Pb}$ & $\mathrm{Zn}$ & $\mathrm{Na}_{2} \mathrm{O}$ & $\mathrm{S}$ & $\mathrm{LOI}$ \\
\hline Gangue & 2.19 & 69.92 & 10.41 & 1.39 & 1.89 & 0.51 & 2.17 & 0.57 & 5.38 & 0.17 & 0.12 & 0.51 & 0.55 & 3.68 \\
Smelting slag & 13.54 & 27.72 & 11.32 & 6.12 & 1.69 & 1.79 & 1.12 & 0.6 & 25.28 & 0.92 & 3.2 & 3.25 & 2.15 & 0.57 \\
\hline
\end{tabular}

Lead-zinc tailings lead and zinc smelting slag and cement clinker were used in the experiment to prepare composite cementitious material. The effect of the species and quantities of hydration products under different ratio of raw materials on mechanical properties was studied, which laid the theoretical foundation for how to prepare cementitious material and optimize its strength. Because external $\mathrm{pH}$ is the main factor affecting the heavy metal leaching, the lead ion leaching of tailings, smelting slag, and tailings-smelting slag cementitious materials under different $\mathrm{pH}$ conditions were studied, respectively, providing basis of suitable environment for the prepared composite cementitious materials.

\section{Experimental}

2.1. Materials and Equipment. In this experiment, the raw materials were lead-zinc tailings, smelting slag, and cement clinker. The additives mainly contained gypsum. The XRD analysis indicated that the main components in the tailings were quartz and kaolinite, and the activation was not difficult. Lead and zinc smelting slag was composed of $\mathrm{SiO}_{2}, \mathrm{FeO}, \mathrm{CaO}$, $\mathrm{Al}_{2} \mathrm{O}_{3}$, and $\mathrm{MgO}$; the main mineral composition was glass phase which meant it was a potential hydraulic material with high activity. The cement clinker came from a cement factory of Baoding, Hebei province. The main compositions are tricalcium silicate, dicalcium silicate, and calcium iron oxide. Chemical composition of lead-zinc tailings and lead-zinc smelting slag was shown in Table 1.

\subsection{Experimentation}

2.2.1. Preparation of Composite Cementing Material. Pregrinding the lead and zinc smelting slag for the raw smelting slag is coarse. Add gypsum and clinker in the fine smelting slag when it was grinded to a certain degree; the final specific surface area of the mixture is $480 \sim 720 \mathrm{~m}^{2} / \mathrm{kg}$. Standard mortar specimen was made according to the "test for cement mortar strength" (ISO, GB/T 17671-1999), and then the specimens were mold unloading and were maintained in $(20 \pm 1)^{\circ} \mathrm{C}$ and humidity above $90 \%$ for 28 days.

2.2.2. Leaching Test. Use a static immersion method to simulate the tailings, smelting slag, and cement products, respectively. In each leaching experiment, $2 \mathrm{~g}$ samples were soaked in a $100 \mathrm{~mL}$ conical flask by the solid to liquid ratio of $1: 25$. The experiment was carried out at room temperature. In order to study the effect of soaking time and initial $\mathrm{pH}$ value on ion release, tailings, smelting slag, and the cement products were soaked in the soaking liquid of the initial $\mathrm{pH}$ values $1,2,3,4,5,6,7,8,9,10,11$, and 12 , respectively. The initial $\mathrm{pH}$ values were adjusted with $\mathrm{NaOH}$ and $\mathrm{HCl}$ solutions; the immersion time was $24 \mathrm{~h}$. The $\mathrm{pH}$ value was adjusted every
TABLE 2: The ratio of materials for smelting slag cementitious.

\begin{tabular}{|c|c|c|c|}
\hline \multirow{2}{*}{ Number } & \multicolumn{3}{|c|}{ Materials } \\
\hline & Additive & Smelting slag & Cement clinker \\
\hline 1 & 5 & 55 & 40 \\
\hline 2 & 5 & 60 & 35 \\
\hline 3 & 5 & 65 & 30 \\
\hline 4 & 5 & 70 & 25 \\
\hline 5 & 10 & 55 & 35 \\
\hline 6 & 10 & 60 & 30 \\
\hline 7 & 10 & 65 & 25 \\
\hline 8 & 10 & 70 & 20 \\
\hline
\end{tabular}

$8 \mathrm{~h}$ during the leaching process to ensure the stability of $\mathrm{pH}$ value.

2.2.3. Analytic Technique. The strength of the sample was tested using a microcomputer controlled electrohydraulic servo pressure testing machine from Changchun new testing machine Co. ltd. The concentration of lead ions was determined by the two xylenol orange spectrophotometric method at the wavelength of $575 \mathrm{~nm}$ by a T6 ultraviolet visible spectrophotometer from Beijing Puxi General Instrument Corp. The $\mathrm{pH}$ value was measured by $\mathrm{pHS}-3 \mathrm{C} \mathrm{pH}$ meter produced by Shanghai Leici instrument factory. The test parameters of scanning electron microscope are as follows: HV $20 \mathrm{KV}$, mag 10000 times, WD $10.1 \mathrm{~mm}$, spot3.0, mode SEI, DET ETD, and HFW $15 \mathrm{um}$. The XRD pattern was determined by X-ray diffraction in the scanning speed of $40 \mathrm{kV} \times 100 \mathrm{~mA}$ and $8^{\circ} / \mathrm{min}$ conditions.

\section{Result and Discussion}

\subsection{Strength Test and Analysis}

3.1.1. Smelting Slag Cementitious Material. Smelting slag cementitious material consists of zinc smelting slag, clinker, and additive. In order to study the influence of smelting slag admixture on the strength of cementitious materials, change the ratio of slag and cement when the amount of admixture is $5 \%$; the specific mixture ratio and property were shown in Table 2 and Figure 1. It can be seen from the chart that the cementitious material bending strength and compressive strength gradually decreased with the increase of smelting waste content. Because of the latent activity of the slag, cement clinker can be used as alkali activator to destroy the vitreous structure of smelting slag. The active $\mathrm{SiO}_{2}$ and $\mathrm{Al}_{2} \mathrm{O}_{3}$ reacted with $\mathrm{Ca}(\mathrm{OH})_{2}$ to form hydrated calcium silicate and hydrated calcium aluminates, resulting in increased strength. The increase of smelting slag resulted in the reduction of 


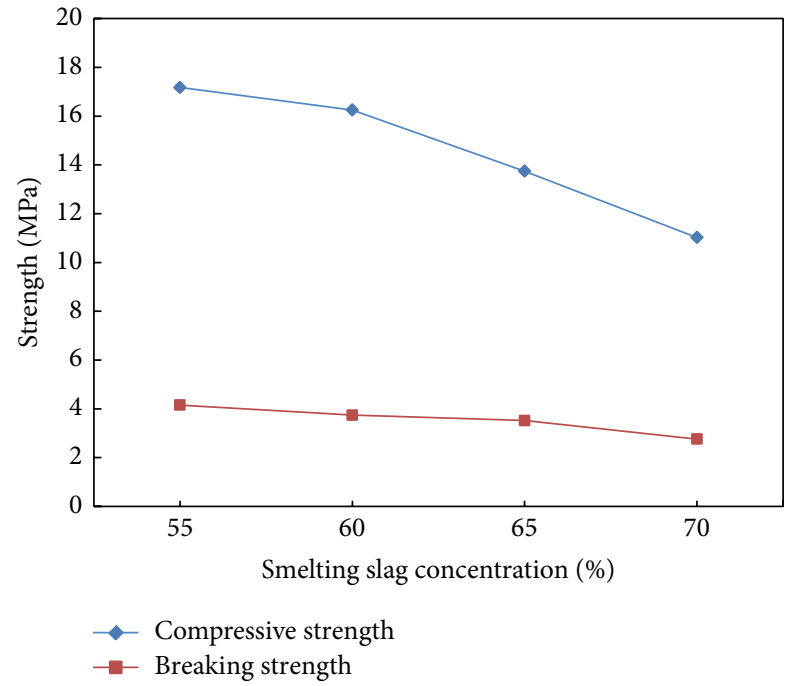

FIGURE 1: Strength among cementitious materials with various smelting concentration.

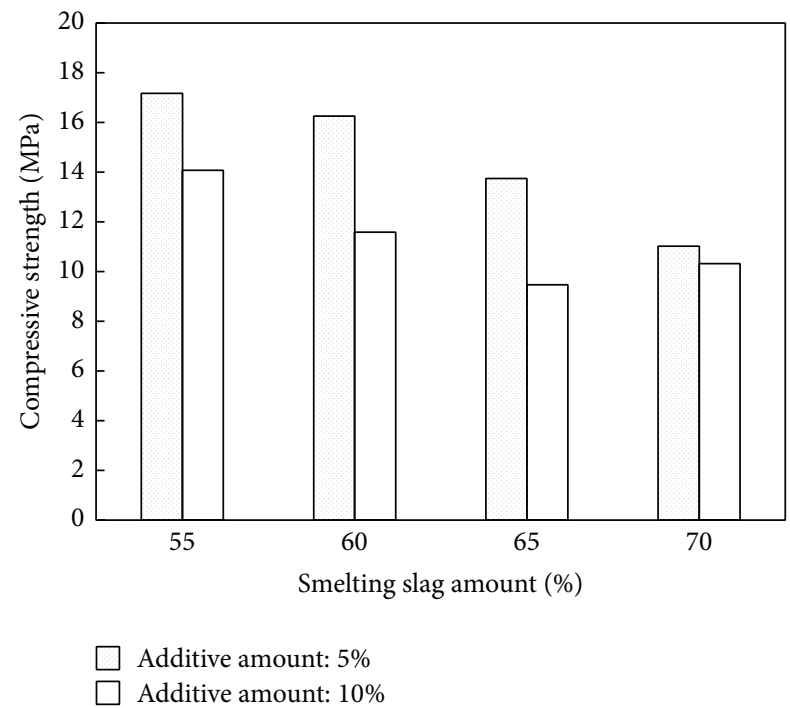

FIGURE 2: Comparison of compressive strength of smelting slag cementitious materials with different additive content.

the proportion of cement clinker in raw materials. When the content of gypsum was too low to inspire all smelting slag, smelting slag existed in hydration and hardening body in the form of low intensity, which led to the decrease of strength of cementitious materials. The influence of different additive dosage on the strength of cementitious materials was shown in Figure 2. On the condition of same smelting slag content, the compressive strength of cementitious material became weak as the additive content increased from $5 \%$ to $10 \%$. The existence of gypsum made it easier to form ettringite when the additive agent was plenty, so that the activity of smelting slag can be taken full advantage of, but, at the same time, the reduced amount of cement clinker in the system led to less calcium hydroxide.

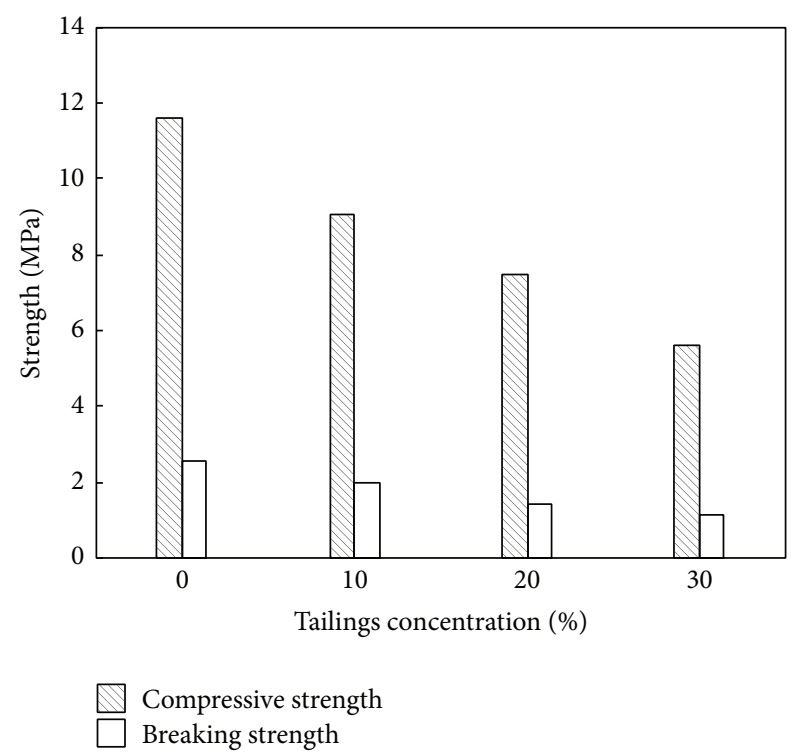

FIGURE 3: Comparison of strength among cementitious materials with different tailing content.

3.1.2. Tailings-Smelting Slag Cementitious Material. For the optimization of comprehensive utilization of solid waste and the comprehensive consideration of economic cost and strength and other factors, appropriately add tailings in the mixture of the proportion of $60 \%$ zinc smelting slag, $30 \%$ cement clinker, and $10 \%$ additive to develop a colored solid waste cementitious material with certain mechanical strength. Figure 3 showed the change of strength with different amount of tailings added when the proportion of smelting slag/clinker/additive was 6/3/1. As can be seen from the figure, the material strength decreased after the tailings were added, which indicated that the addition of the lead-zinc tailings goes against the improvement of the mechanical properties of cementitious material. In order to meet the strength requirements, the tailings added in cementitious materials should be limited [6].

3.1.3. SEM Analysis. The scanning electron micrographs of different smelting slag admixture cementitious material when the amount of additive was 10\% was shown (Figure 4), and the magnification was 1000 times. The microstructure of smelting slag cementitious material can be briefly described as follows: needle shaped ettringite crystals and flocculent C$\mathrm{S}$-H gel overlapped to form a spatial network structure, and it filled the surface and holes and simultaneously mixed the unreacted dehydrate gypsum and slag particles together to form a whole. When the slag content was $55 \%$, the hydration products were ettringite, which was in the initial stage of growth, and fiber was short and dense; independent existence of slag almost cannot be seen; when the slag content was $60 \%$, the hydration products were C-S-H gel and flaky calcium hydroxide; when the slag content increased up to $65 \%$, the structure of the material was loose and the raw material component was exposed; part of C-S-H gel and ettringite were produced. When the content of smelting slag was 55\%, 


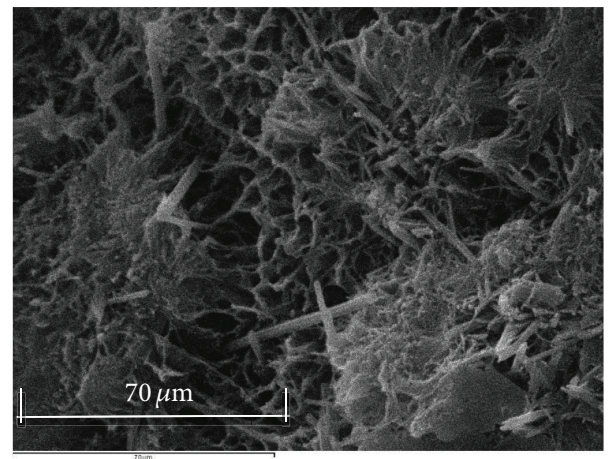

(a)

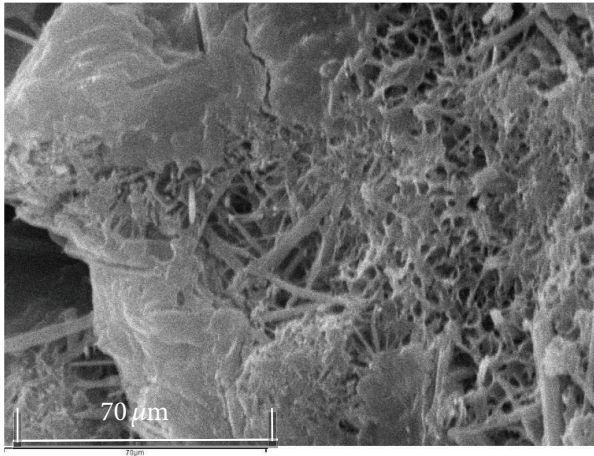

(b)

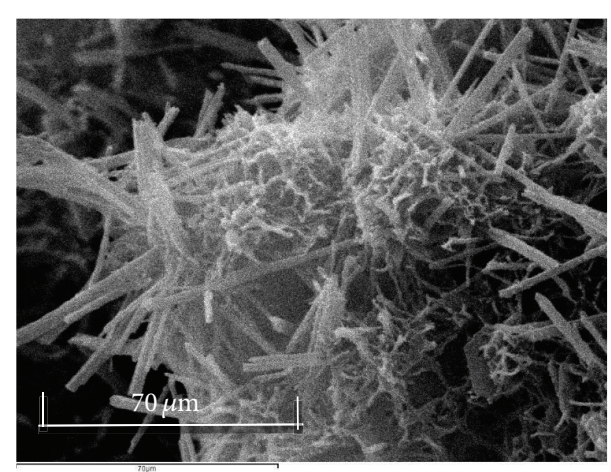

(c)

FIGURE 4: SEM photos of hydration products with different smelting slag content: (a) 55\%; (b) 60\%; (c) $65 \%$.

needle-like AFt crystals in the mortar formed skeleton, and the structure of hardened pastes continuously compacting through the well-distributed filling of C-S-H gel, thus increasing the strength of cementing filling material; this explained the reason why the strength of mortar with 55\% smelting slag content was higher than that of the other samples from the point of microstructure, while with the increase of smelting slag in the sample, $\mathrm{Ca}(\mathrm{OH})_{2}$ crystal increased, calcium silicate hydrate $(\mathrm{C}-\mathrm{S}-\mathrm{H})$ gel decreased, and the structure was more loose; this also explained the gradual decrease of compressive strength of the samples from the point of microstructure.

\subsection{Leaching Experiment}

3.2.1. Effect of $p H$ on Lead Ion Leaching Amount. Generally, $\mathrm{pH}$ value of the leaching solution is an important factor influencing heavy metal leaching process, for the $\mathrm{pH}$ value can affect not only the physicochemical properties of the adsorbent surface but also the existence state of heavy metal ions after being leached. The leaching of lead ion of tailings, smelting slag and tailings, smelting slag cementitious materials under different $\mathrm{pH}$ conditions was studied in this experiment. The $\mathrm{pH}$ value was installed in the range of 1 to 12 and the experimental results were shown in Figure 5. It was not difficult to find out that in the same $\mathrm{pH}$ environment, lead ion leaching smelting slag quantity $>$ lead ion leaching tailings in quantity $>$ lead ion leaching cementitious materials body weight. Therefore, making the smelting slag and tailings

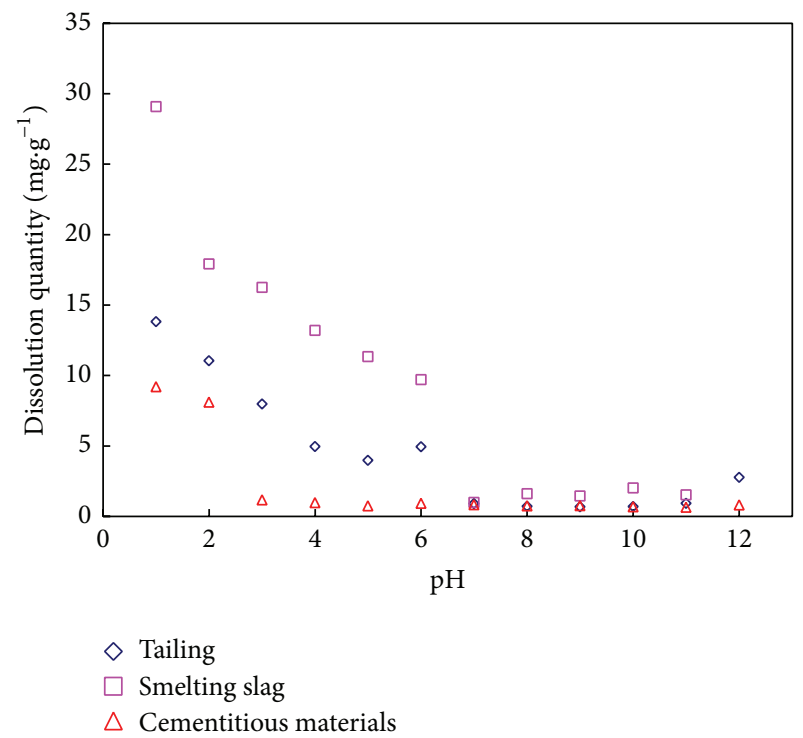

FIGURE 5: The influence of $\mathrm{pH}$ on leaching amount.

into cementitious materials fixed lead ions and reduced the leaching. With the increase of $\mathrm{pH}$ value of leaching liquids, the trend of lead ion leaching from tailings and metallurgical slag were decreased alike. When the $\mathrm{pH}<7$, the lead ion leaching amount was quite high and decreased significantly 
with the increase of $\mathrm{pH}$ value; when the $\mathrm{pH} \geq 7$, the lead ion leaching rate was maintained at a low level. This was because, in an acidic environment, it was easy for metal to form soluble metal oxides, and stronger solubility made lead ions more susceptible to leaching, while heavy metals might combine with $\mathrm{OH}^{-}$or silicate and form into calcium salts in the alkaline environment, existed in a state of stable insoluble [7], so that the leaching amount of lead ion reduced. In addition, the curve of lead ion leaching from cementitious materials versus $\mathrm{pH}$ showed that when $\mathrm{pH}<3$, lead ion leaching amount obviously decreased with the increase of $\mathrm{pH}$, and when $\mathrm{pH} \geq 3$, lead ion leaching quantity slightly decreased with the increase of $\mathrm{pH}$ and kept at a low level; therefore, the preparation of smelting waste and tailings being made into cementitious materials can not only reduce the amount of lead ion leaching but also keep a low leaching amount of lead ion from cementing material in arrange of pH 3-12.

3.2.2. Effect of Time on the Leaching of Lead Ions. Under the condition of $\mathrm{pH}$ environment $(\mathrm{pH}=9 \sim 10)$ of the leaching solution, solid to liquid ratio was $1: 25$ and $293( \pm 1)$ constant temperature, the effect of leaching time on the lead ion leaching from smelting slag, tailings, and cementitious materials was studied, and the experimental results were shown in Figure 6. The equilibrium times of lead ion leaching from smelting slag, tailings, and cementitious materials, respectively, were $60 \mathrm{~min}, 80 \mathrm{~min}$, and $40 \mathrm{~min}$, the lead ion leaching amount when the balance was achieved: smelting slag $>$ tailings $>$ cementitious materials. Hence one can see that preparing cementitious materials by smelting slag and tailings can effectively reduce the leaching of heavy metals of lead ions; this is because the alkaline slag cementitious material hydration products $t(\mathrm{pH}=12)$ can urge heavy metal ions such as $\mathrm{Pb}$ to form insoluble metal oxides and hydroxides, thereby adsorbed on the surface of charged ettringite or precipitated in C-S-H sol pore; this reaction was also the main mechanism of cement solidification of heavy metals. In addition, the additive containing anhydrous gypsum caused the high concentration of sulfate in hydration products of cementitious materials, and in the high concentration of sulfate, heavy metal ions are contained by ettringite crystal [8]. Compare the condition of less sulfate concentration in cement; it can be considered that the high sulfate concentration in HAS hydration products is the reason of low concentration of heavy metal filtrate of cementitious material solidified body.

For the better comparison of leaching process of 3 samples to reach equilibrium, the experimental data was fitted by the quasi-two-level dynamic model; the equation is as follows [9]:

$$
\frac{t}{q_{t}}=\frac{1}{K_{s} q_{e}^{2}}+\frac{1}{q_{e}} t
$$

where $q_{e}$ and $q_{t}$ are, respectively, the equilibrium time and adsorption amount of HA when the time is $t(\mathrm{~min})$ and $K_{s}$ $\left(\mathrm{g} \cdot(\mathrm{mg} \cdot \mathrm{min})^{-1}\right)$ is the quasi-two-level kinetic constant.

The quasi-two-level dynamic simulation curves of each lead ion leaching samples were shown in Figure 7. According

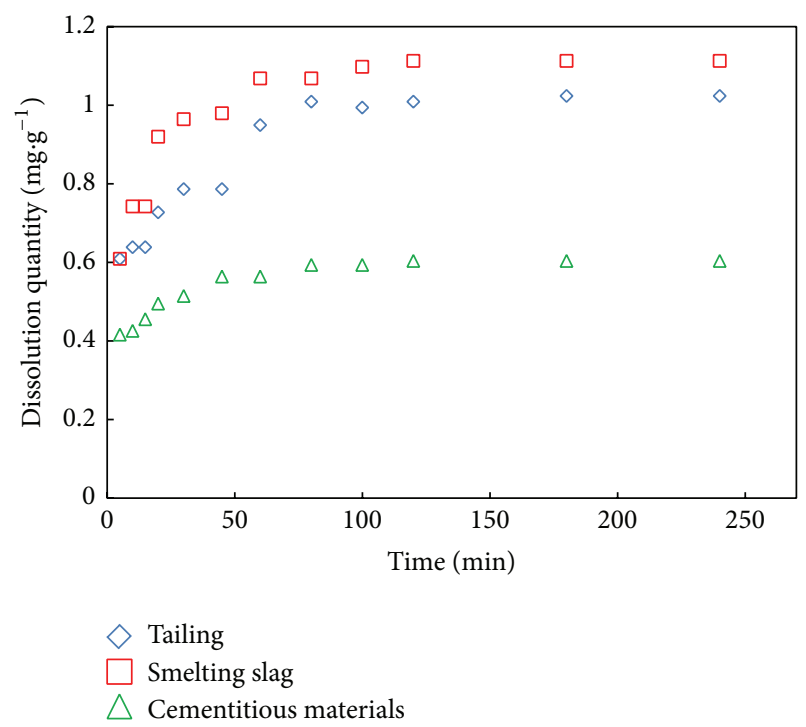

FIGURE 6: Dissolution quantity of different sample with time.

to the slope and intercept of the curve, quasi-two-level kinetic constant $K_{s}$ and the theoretical leaching amount of equilibrium $q_{e(\text { cal }}$ and determination coefficient $R^{2}$ can be calculated, and the actual leaching amount of equilibrium $q_{e(\exp )}$ was shown in Table 3 . The determination coefficient $R^{2}$ value of three kinds of samples measured by the quasitwo-level dynamic model fitting curve was 0.9981, 0.9996, and 0.9998, and the leaching amount of balance theory and the actual amount is consistent thus quasi-two-stage dynamic model can be used to describe the leaching behavior of lead ion of the three kinds of samples. It can be calculated by comparison of kinetic constants that $K_{s C}>K_{s S}>K_{s \mathrm{~T}}$. The tailings and metallurgical slag prepared into cementitious materials can shorten the equilibrium time required for lead ion leaching, which can reduce the amount of lead ions.

\section{Conclusion}

Making smelting slag and lead-zinc tailings as the basic components, mixed with right amount of clinker and gypsum additive, can prepare a cementitious material with good performance and have a fixed effect on the heavy metal lead in the smelting slag and tailings to reduce the leaching amount of lead ion.

(1) The strength of gel materials decline with the increase of smelting slag content.

(2) The addition of this kind of lead-zinc tailings goes against the improvement of the mechanical properties of the cementitious material so that the dosage should be controlled within $10 \%$.

(3) The preparation of composite cementitious materials by smelting slag and tailings can effectively reduce the leaching of heavy metals lead and can keep low leaching quantity in a wide range of $\mathrm{pH}$ value. 
TABLE 3: The quasi-two-level dynamic model equation data.

\begin{tabular}{|c|c|c|c|c|}
\hline Sample & $q_{e(\exp )} / \mathrm{mg} \cdot \mathrm{g}^{-1}$ & $q_{e(\mathrm{cal})} / \mathrm{mg} \mathrm{g}^{-1}$ & $K_{s} / g \cdot(\mathrm{mg} \cdot \min )^{-1}$ & $R^{2}$ \\
\hline Tailing & 1.0234 & 1.0656 & 0.1130 & 0.9981 \\
\hline Smelting slag & 1.1123 & 1.1446 & 0.1586 & 0.9996 \\
\hline Cementitious materials & 0.6033 & 0.6169 & 0.3716 & 0.9998 \\
\hline
\end{tabular}

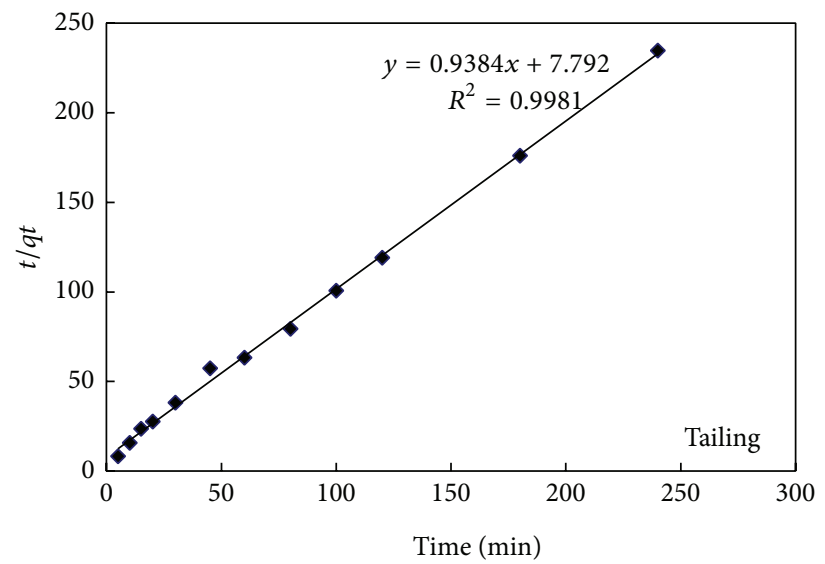

(a)

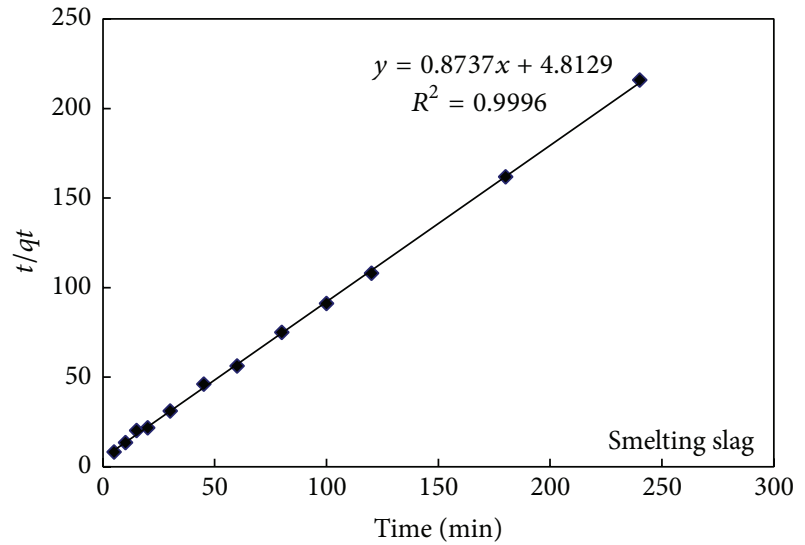

(b)

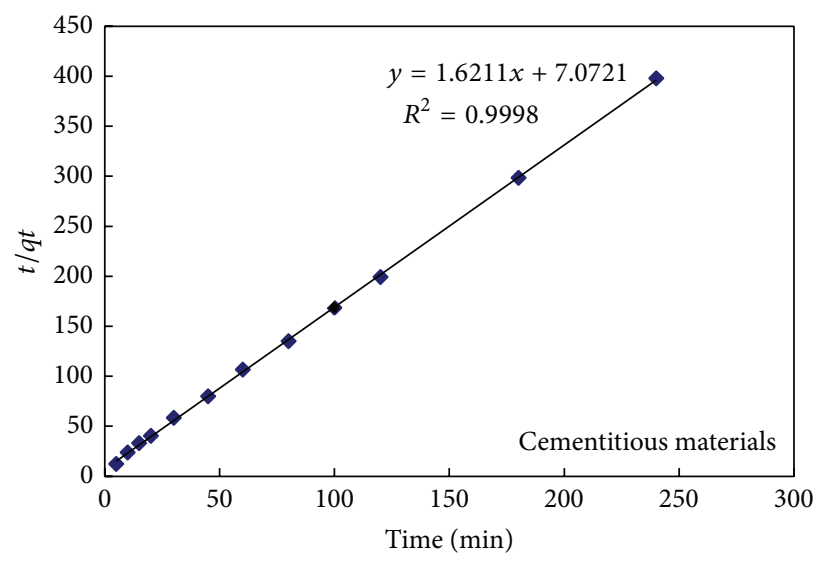

(c)

Figure 7: The quasi-two-level dynamic model of three samples.

(4) The quasi-two-level dynamic model can fit well with the leaching curves of lead ion leach from smelting slag, tailings, and cementitious materials by the time. The model can be used to describe leaching behavior of lead ion in the three samples.

\section{Conflict of Interests}

The authors declare that there is no conflict of interests regarding the publication of this paper.

\section{Acknowledgment}

This research was funded by International S \& T Cooperation (no. 2014DFA70760).

\section{References}

[1] M. Manzano, C. Ayora, C. Domenech, P. Navarrete, A. Garralon, and M.-J. Turrero, "The impact of the Aznalcollar mine tailing spill on groundwater," Science of the Total Environment, vol. 242, no. 1-3, pp. 189-209, 1999.

[2] R. S. Sharma and T. S. Al-Busaidi, "Groundwater pollution due to a tailings dam," Engineering Geology, vol. 60, no. 1-4, pp. 235244, 2001.

[3] S. Yin, A. Wu, K. J. Hu, Y. Wang, and Y. Zhang, "The effect of solid components on the rheological and mechanical properties of cemented paste backfill," Minerals Engineering, vol. 35, pp. 6166, 2012.

[4] S. A. Shaw, T. A. Al, and K. T. B. MacQuarrie, "Mercury mobility in unsaturated gold mine tailings, Murray Brook mine, New Brunswick, Canada," Applied Geochemistry, vol. 21, no. 11, pp. 1986-1998, 2006. 
[5] A. Allahverdi and S. Ahmadnezhad, "Mechanical activation of silicomanganese slag and its influence on the properties of Portland slag cement," Powder Technology, vol. 251, pp. 41-51, 2014.

[6] S. H. Yin and Y. Wang, "Influence of mud height on the concentrastion of the fine tailing," Science and Technology Review, vol. 30, no. 7, pp. 29-33, 2012.

[7] R. D. Spence, Chemistry and Microstructure of Solidified Waste Forms, CRC Press, 1992.

[8] R. K. Vempati, M. Y. A. Mollah, A. K. Chinthala, D. L. Cocke, and J. H. Beeghly, "Solidification/stabilization of toxic metal wastes using coke and coal combustion by-products," Waste Management, vol. 15, no. 5-6, pp. 433-440, 1995.

[9] G. Lü, J. Hao, L. Liu et al., “The adsorption of phenol by lignite activated carbon," Chinese Journal of Chemical Engineering, vol. 19, no. 3, pp. 380-385, 2011. 

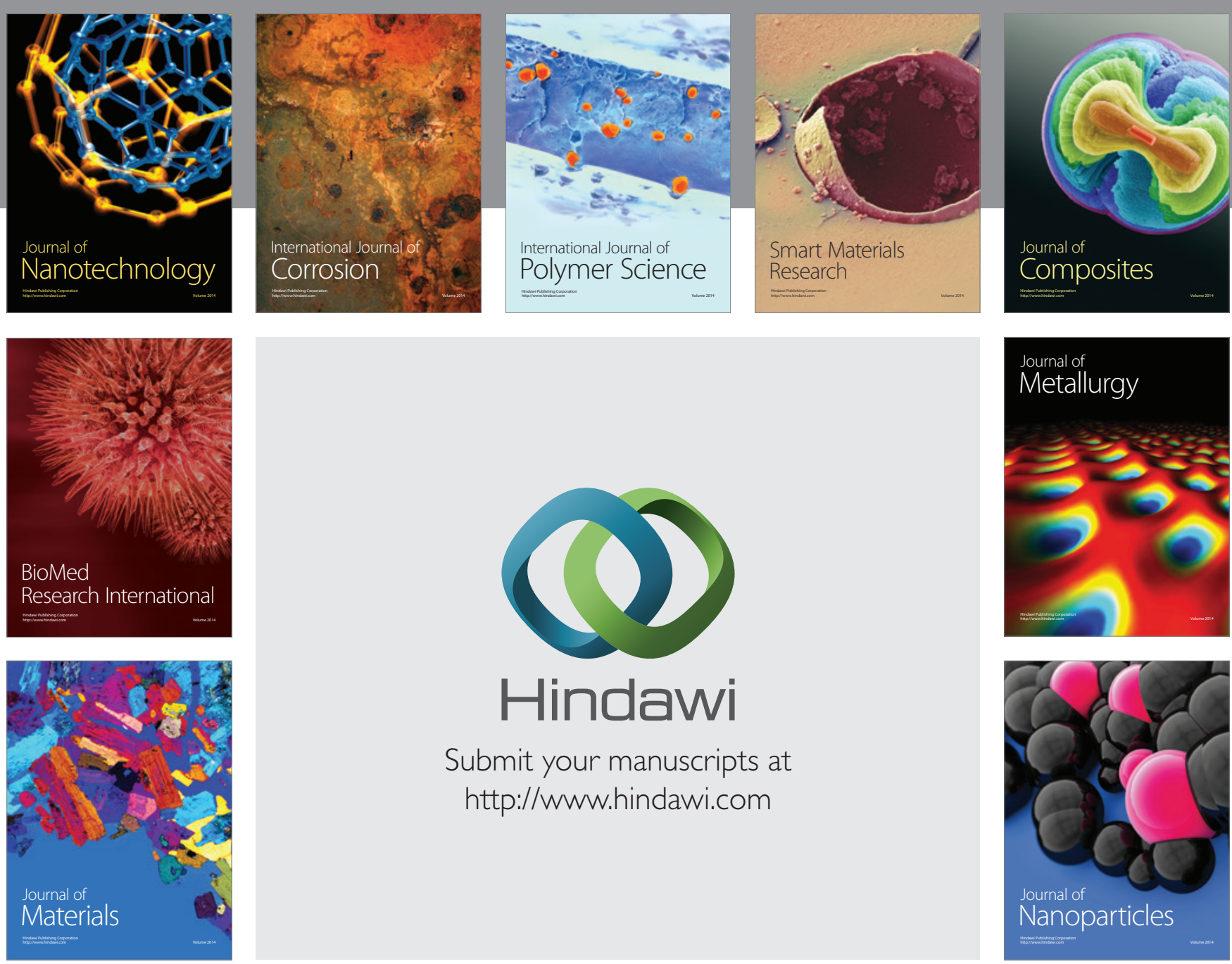

Submit your manuscripts at http://www.hindawi.com
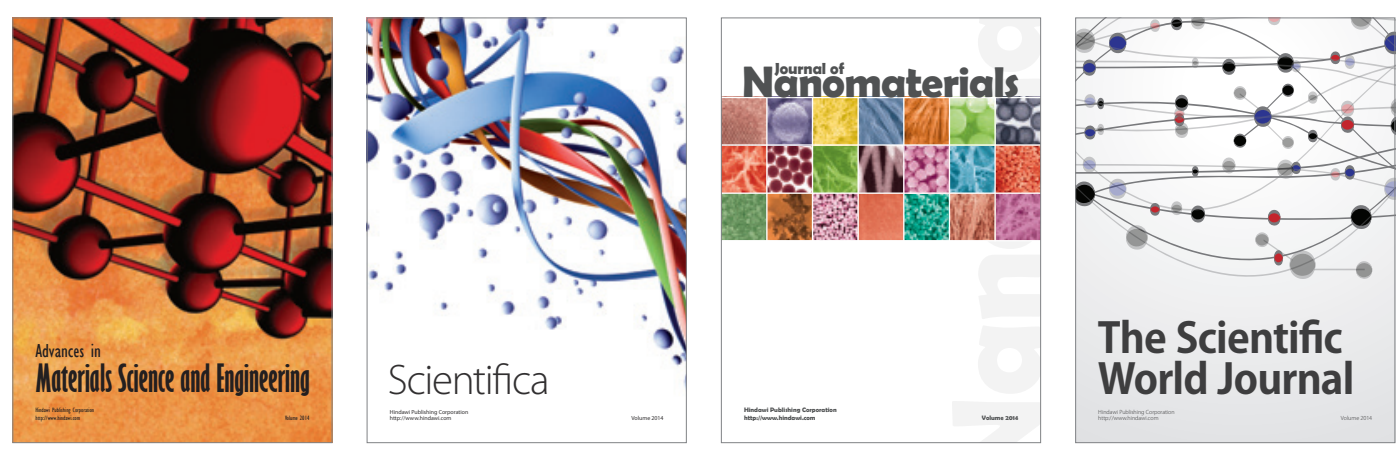

\section{The Scientific World Journal}
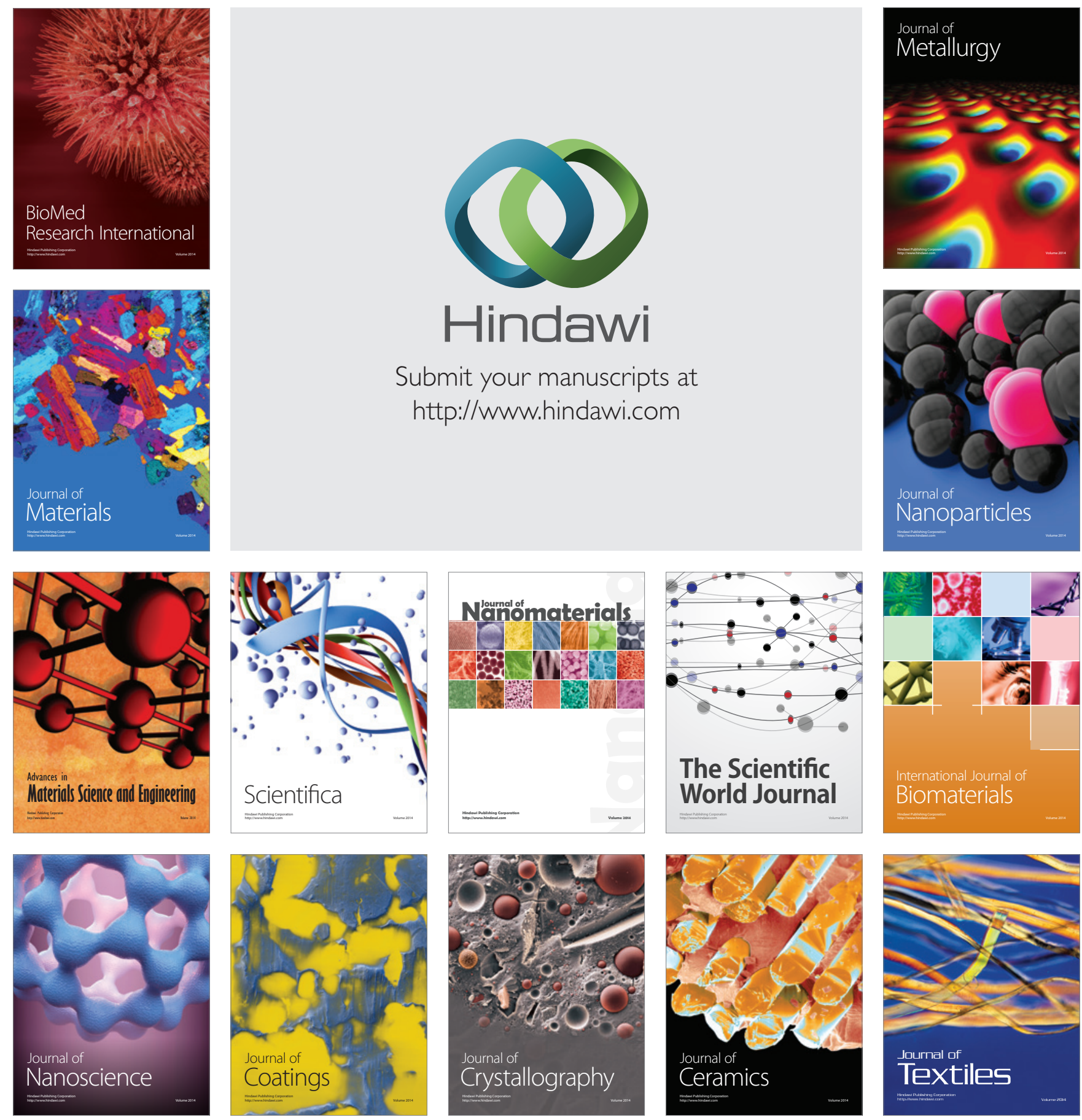